\title{
Study of the Molecular Properties of Mono- and Binuclear Metal $s$-Indacenyl Complexes with Ir, Rh, and Re: A Theoretical Approach
}

\author{
Ximena Zarate, ${ }^{1}$ Eduardo Schott, ${ }^{2}$ Emilio Bunel, ${ }^{3}$ Juan M. Manríquez, ${ }^{2}$ and Ivonne Chávez \\ ${ }^{1}$ Instituto de Ciencias Químicas Aplicadas, Facultad de Ingeniería, Universidad Autónoma de Chile, \\ Av. Pedro de Valdivia 425, Santiago, Chile \\ ${ }^{2}$ Departamento de Química Inorgánica, Facultad de Química, Pontificia Universidad Católica de Chile, Casilla 306, Santiago, Chile \\ ${ }^{3}$ Argonne National Laboratory, Argonne, IL 60439, USA
}

Correspondence should be addressed to Ximena Zarate; jazminac@gmail.com and Ivonne Chávez; ichavez@uc.cl

Received 31 March 2017; Accepted 2 May 2017; Published 1 June 2017

Academic Editor: Henryk Kozlowski

Copyright (c) 2017 Ximena Zarate et al. This is an open access article distributed under the Creative Commons Attribution License, which permits unrestricted use, distribution, and reproduction in any medium, provided the original work is properly cited.

\begin{abstract}
Density functional theory (DFT) calculations were performed on a new family of mono- and bimetallic complexes, containing 4,8-([10] paracyclophane)-1,5-dihydro-s-indacene as the bridging ligand between the two metallic centers and different ancillary ligands. The $s$-indacene was blocked by substitution of the central benzene ring with the [10]paracyclophane to obtain the synconformations. This would force the metallic centers to be close together. It is proposed, due to the calculated molecular and electronic properties such as the reactivity indexes, the delocalized nature of the $s$-indacenyl ligand, and the electron-rich metals, that these systems could be reactive in a catalytic reaction. The results indicate that the systems with Rh and Re holding ancillary ligands such as bipy and CO show the best properties to be active in a chemical reaction. In this sense, by the assessed geometrical and electronic properties, when compared with a previously reported system, these complexes could be candidates for the reduction of $\mathrm{CO}_{2}$ to oxalate.
\end{abstract}

\section{Introduction}

$s$-Indacene and as-indacene belong to a class of conjugated hydrocarbons characterized by having $4 n \pi$ electrons $(n=$ 2,3). Therefore, according to Hückel's Rule, they should be antiaromatic [1]. Nevertheless, they have been for decades of significant interest for organic chemists as they have focused on them upon their diverse and fascinating reactivity. Due to the synthetic challenges that these kinds of compounds present and the questions that have arisen over their aromaticity and structure, the potential of these systems in different applications, such as semiconducting devices and catalysis, has been slowly explored.

Even when the unsubstituted molecules are unstable, their dianions and several substituted derivatives stabilize both sterically and electronically, resulting in thermally stable structures at room temperature [2].
Moreover, $s$-indacene may connect two or more organometallic centers, which may have different oxidation states, and allow interaction between them. Binuclear metal complexes bearing an as-indacenyl or $s$-indacenyl ligand were first reported in the literature in 1988 [3, 4]. A large variety of transition metals homobinuclear complexes have been described including $\mathrm{Fe}, \mathrm{Co}, \mathrm{Ni}, \mathrm{Ru}, \mathrm{Rh}, \mathrm{Re}$, and $\mathrm{Mn}$. Also, heterobinuclear complexes with combinations of metals such as $\mathrm{Rh}-\mathrm{Ru}, \mathrm{Fe}-\mathrm{Ru}, \mathrm{Fe}-\mathrm{Rh}, \mathrm{Ru}-\mathrm{Rh}, \mathrm{F}-\mathrm{Co}$, and $\mathrm{Cr}-\mathrm{Ni}$ have been reported [5-8]. The most striking feature of this family of binuclear complexes is the ability to delocalize charge among metal centers upon oxidation. In this sense, we believe that bimetallic complexes are useful compounds that might induce catalytic reactions.

On the other hand, literature reports on the selective conversion of $\mathrm{CO}_{2}$ to oxalate $\left(\mathrm{C}_{2} \mathrm{O}_{4}\right)^{2-}$ point to the occurrence of a two-metal-centers mechanism. Bi- or polymetallic 


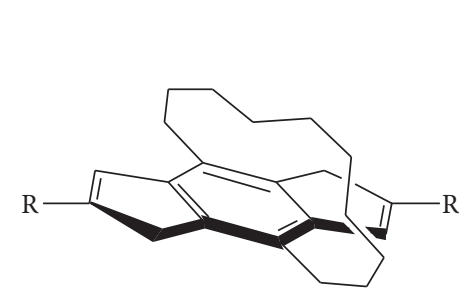

(a)

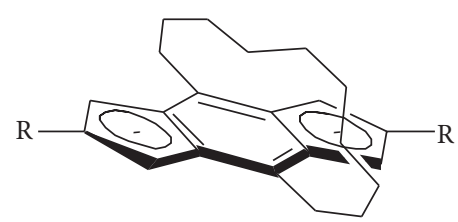

(b)

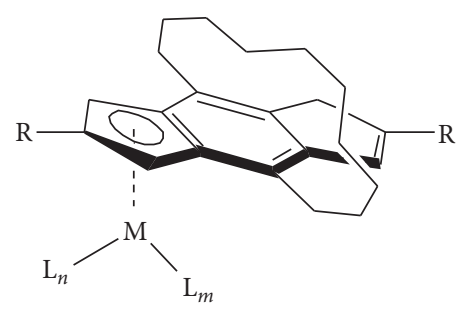

(c)

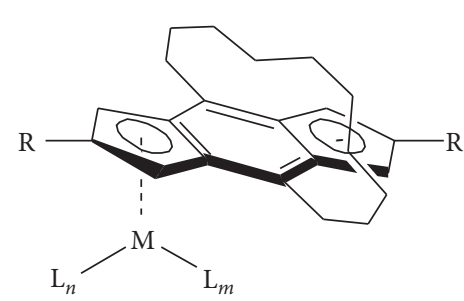

(d)

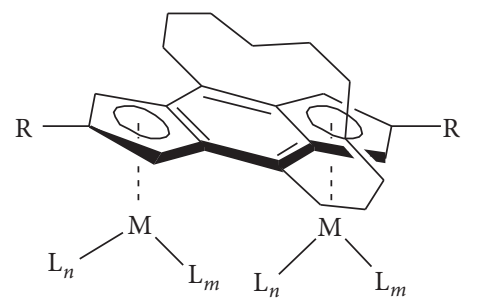

(e)

FIgURE 1: Structures of the studied systems. (a) Neutral ligand, (b) dianion ligand, and (c) neutral monometallic, (d) monoanion monometallic, and (e) bimetallic systems. $\mathrm{R}=\mathrm{H}, \mathrm{CH}_{3}$, and $\mathrm{CH}_{2} \mathrm{CH}_{3} ; \mathrm{M}=\mathrm{Ir}, \mathrm{Rh}$, and $\mathrm{Re} ; \mathrm{L}_{m}$ and $\mathrm{L}_{n}=$ bipy, $\mathrm{CO}$, with $m$ and $n=0,1,2$, 3.

compounds have been studied showing a wide variation of results [9-12]. The most important conclusion of these reports is that, for systems where the coordination of $\mathrm{CO}_{2}$ is not reversible, the ability to transform $\mathrm{CO}_{2}$ into other compounds depends on the extent of the charge transfer from the transition metal to $\mathrm{CO}_{2}$. If the metal transfers an electron, the formation of $\mathrm{C}-\mathrm{C}$ bonds is possible and the rigidity of the bimetallic system seems to play an essential role in the formation of this bond $[13,14]$. In this sense, interestingly, one of the most innovative works in the area of $\mathrm{CO}_{2}$ reduction reported by Angamuthu et al. in 2010 consists in the synthesis of a tetranuclear complex of $\mathrm{Cu}(\mathrm{I})$ with the ligand $\mathrm{N}$ (2-mercaptopropyl)-N,N-bis(2-pyridylmethyl)amine, which spontaneously and selectively captures $\mathrm{CO}_{2}$ from the air [15]. $\mathrm{Cu}(\mathrm{I})$ gets oxidized to $\mathrm{Cu}(\mathrm{II})$ and a bridge of oxalate is formed, which links two binuclear complexes, forming a tetramer. Adding a lithium salt to the solution allows the quantitative precipitation of lithium oxalate. Finally, the $\mathrm{Cu}(\mathrm{I})$ complex can be recovered by electrochemical reduction. The crystallographic study of the $\mathrm{Cu}$ complex showed that the $\mathrm{Cu}$ Cu distance in the complex was $5.43 \AA$. This distance is similar to the $\mathrm{Rh}-\mathrm{Rh}$ distance observed in a syn binuclear complex synthesized by our group [(2,6-diethyl-4,8-dimethyl-sindacenediide) $\left.\{\mathrm{Rh}(\mathrm{COD})\}_{2}\right][16]$ of about $5.5 \AA$.

The large majority of the examples of binuclear complexes with $s$-indacene reported in the literature show the two metals centers in an anticonfiguration. This is due mostly to the steric bulk imposed by the ancillary ligands. In this work, we propose that it is possible to avoid the anticonfiguration by blocking one of the faces of the $s$-indacene introducing a group that can effectively obstruct the access of the metals to both faces forcing them to adopt the syn configuration. This could be easily achieved by constructing a cyclophane structure over the plane of the rings as shown in Figure 1.

Therefore, in order to have the right template structure for coupling reactions in those compounds and to favor the reaction, the right Metal-Metal (M-M) distance, electronic configuration, and lability of the ligand coordinated to the metal center (ancillary ligands) are needed. Specifically, binuclear metal frameworks could play an important role as templates for these types of reactions, such as selective reductive coupling of two molecules of $\mathrm{CO}_{2}$ to oxalate.

Inspired by the work of Bouwman et al. and the versatile indacene derivatives, we decided to propose templates with synthetical feasibility, consisting in a family of binuclear metal complexes.

The aim of this work is to evaluate the effect of different transition metals ( $\mathrm{Ir}, \mathrm{Rh}$, and $\mathrm{Re}$ ), different ancillary ligands (bipy and $\mathrm{CO}$ ), and - $\mathrm{R}$ groups $\left(\mathrm{CH}_{3}\right.$ and $\left.\mathrm{CH}_{2} \mathrm{CH}_{3}\right)$ (Figure 1) over the electronic properties, assessing the Frontier Molecular Orbitals (FMOs) location, the geometrical parameters highlighting the $\mathrm{M}-\mathrm{M}$ distance, the global reactivity indexes, the atomic metal charges, and the Fukui functions. This preliminary study could lead experimentalist to have a hint about which metallic $s$-indacenyl complexes, ancillary ligands, and peripheral substituents might show suitable properties for a variety of chemical applications.

\section{Computational Details}

Quantum chemical calculations were performed in order to further investigate the electronic structure of a family of compounds in the ground state. Density functional theory (DFT) as implemented in Gaussian 09 [17] software was used to perform the calculations of the studied systems. The Becke three-parameter hybrid functional combined with Lee-YangParr correlation B3LYP $[18,19]$ was employed. The relativistic effects of the heavy metals were incorporated using the pseudopotential LANL2DZ [20-22] and the Gaussian basis sets 6-31G(d) were used for the nonmetallic atoms [23]. With the aim of getting the minima points over the potential energy surface of the proposed compounds, the molecular structures 
TABLE 1: Selected geometrical parameters of the ground state conformers. Bond lengths are given in Angstrom $(\AA)$ (see Scheme 1).

(a)

\begin{tabular}{lccccccccc}
\hline Par. Geo. & \multicolumn{3}{c}{$\mathrm{M}=\mathrm{Ir}, \mathrm{L}_{n}=$ bipy } & \multicolumn{3}{c}{$\mathrm{M}=\mathrm{Rh}, \mathrm{L}_{n}=$ bipy } & \multicolumn{3}{c}{$\mathrm{M}=\mathrm{Re}, \mathrm{L}_{n, m}=$ bipy, CO } \\
& $\mathrm{H}$ & $\mathrm{CH}_{3}$ & $\mathrm{CH}_{2} \mathrm{CH}_{3}$ & $\mathrm{H}$ & $\mathrm{CH}_{3}$ & $\mathrm{CH}_{2} \mathrm{CH}_{3}$ & $\mathrm{H}$ & $\mathrm{CH}_{3}$ & $\mathrm{CH}_{2} \mathrm{CH}_{3}$ \\
\hline M1-C1 & 2.22 & 2.22 & 2.21 & 2.23 & 2.22 & 2.22 & 2.25 & 2.24 & 2.24 \\
M1-C2 & 2.15 & 2.16 & 2.16 & 2.20 & 2.20 & 2.20 & 2.22 & 2.24 & 2.24 \\
M1-C3 & 2.22 & 2.21 & 2.22 & 2.23 & 2.22 & 2.22 & 2.32 & 2.31 & 2.31 \\
M1-C9 & 2.61 & 2.58 & 2.59 & 2.57 & 2.56 & 2.56 & 2.52 & 2.51 & 2.51 \\
M1-C10 & 2.62 & 2.59 & 2.60 & 2.57 & 2.56 & 2.57 & 2.53 & 2.52 & 2.52 \\
M2-C5 & 2.22 & 2.22 & 2.22 & 2.23 & 2.23 & 2.23 & 2.25 & 2.25 & 2.25 \\
M2-C6 & 2.16 & 2.16 & 2.16 & 2.20 & 2.21 & 2.21 & 2.22 & 2.24 & 2.24 \\
M2-C7 & 2.22 & 2.22 & 2.21 & 2.23 & 2.22 & 2.22 & 2.32 & 2.31 & 2.31 \\
M2-C11 & 2.60 & 2.60 & 2.61 & 2.57 & 2.56 & 2.55 & 2.52 & 2.51 & 2.51 \\
M2-C12 & 2.61 & 2.60 & 2.61 & 2.57 & 2.56 & 2.56 & 2.52 & 2.52 & 5.43 \\
M1-M2 & 5.58 & 5.53 & 5.59 & 5.45 & 5.43 & 5.41 & 5.40 & 5.43 & 5.44 \\
\hline
\end{tabular}

(b)

\begin{tabular}{lccccccccc}
\hline \multirow{2}{*}{ Par. Geo. } & \multicolumn{3}{c}{$\mathrm{M}=\mathrm{Ir}, \mathrm{L}_{n, m}=\mathrm{CO}$} & \multicolumn{3}{c}{$\mathrm{M}=\mathrm{Rh}, \mathrm{L}_{n, m}=\mathrm{CO}$} & \multicolumn{3}{c}{$\mathrm{M}=\mathrm{Re}, \mathrm{L}=(\mathrm{CO})_{3}$} \\
& $\mathrm{H}$ & $\mathrm{CH}_{3}$ & $\mathrm{CH}_{2} \mathrm{CH}_{3}$ & $\mathrm{H}$ & $\mathrm{CH}_{3}$ & $\mathrm{CH}_{2} \mathrm{CH}_{3}$ & $\mathrm{H}$ & $\mathrm{CH}_{3}$ & $\mathrm{CH}_{2} \mathrm{CH}_{3}$ \\
\hline M1-C1 & 2.29 & 2.28 & 2.28 & 2.28 & 2.27 & 2.27 & 2.33 & 2.33 \\
M1-C2 & 2.25 & 2.26 & 2.26 & 2.27 & 2.29 & 2.28 & 2.32 & 2.34 \\
M1-C3 & 2.29 & 2.28 & 2.28 & 2.28 & 2.27 & 2.27 & 2.34 & 2.32 & 2.34 \\
M1-C9 & 2.65 & 2.64 & 2.64 & 2.60 & 2.58 & 2.59 & 2.50 & 2.50 & 2.33 \\
M1-C10 & 2.65 & 2.65 & 2.65 & 2.60 & 2.59 & 2.59 & 2.52 & 2.50 & 2.49 \\
M2-C5 & 2.29 & 2.28 & 2.28 & 2.28 & 2.27 & 2.27 & 2.32 & 2.33 & 2.32 \\
M2-C6 & 2.25 & 2.26 & 2.26 & 2.27 & 2.28 & 2.28 & 2.32 & 2.34 & 2.34 \\
M2-C7 & 2.29 & 2.28 & 2.28 & 2.28 & 2.27 & 2.27 & 2.34 & 2.32 & 2.33 \\
M2-C11 & 2.66 & 2.65 & 2.65 & 2.59 & 2.59 & 2.59 & 2.49 & 2.50 & 2.49 \\
M2-C12 & 2.66 & 2.65 & 2.65 & 2.60 & 2.59 & 2.59 & 2.52 & 2.49 & 2.51 \\
M1-M2 & 5.58 & 5.60 & 5.61 & 5.41 & 5.40 & 5.44 & 5.08 & 5.05
\end{tabular}

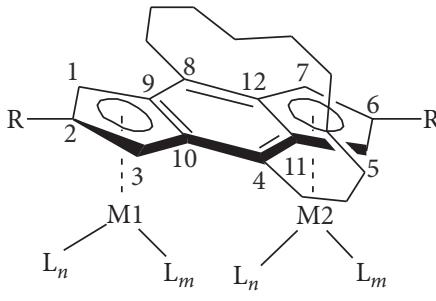

SCHEME 1

were fully optimized without symmetry constriction and the frequency calculations were performed at the same level of theory to confirm that all the optimized systems are stationary minima points. Implicit solvation effects were incorporated using the polarized continuum model (PCM, $\varepsilon=7.426$ ) for tetrahydrofuran [24]. The local reactivity indexes and the Fukui functions computed at the ground state geometry are also assessed and analyzed.

\section{Results and Discussion}

The optimized ground state minima of the series of compounds displayed in Figure 1, ligand (s-Ic) in the neutral and dianion states, and the mononuclear and binuclear coordination systems were obtained at the B3LYP/6-31G(d) + PCM $(\varepsilon=7.426)$ level of theory. Selected geometrical parameters of the corresponding minima are listed in Table 1.

The ligand s-Ic shows a planar structure and one plane face is blocked by substitution of the central benzene ring with a saturated alkyl chain formed by $10-\mathrm{CH}_{2}$ - units. This substitution is a proposal for experimentalist to synthesize the compounds adopting exclusively the syn conformation after metallic coordination.

Geometrical parameters such as $\mathrm{C}-\mathrm{C}$ and $\mathrm{C}-\mathrm{H}$ of the sIc coordinating different metals (not shown in Table 1) do not change significantly when all the studied compounds are compared as some values show differences in the third decimal digit or in less proportion in the second decimal digit. This indicates that the different metals and ancillary ligands do not lead to significant changes in the structural geometry of the s-Ic.

Regarding the M-M distances, as observed in Table 1, the binuclear transition metals frameworks show the appropriate length between the two metal centers to act as a template for the selective reduction of two molecules of $\mathrm{CO}_{2}$ to oxalate. Specifically, the results show that the systems with $\mathrm{Rh}$ and 


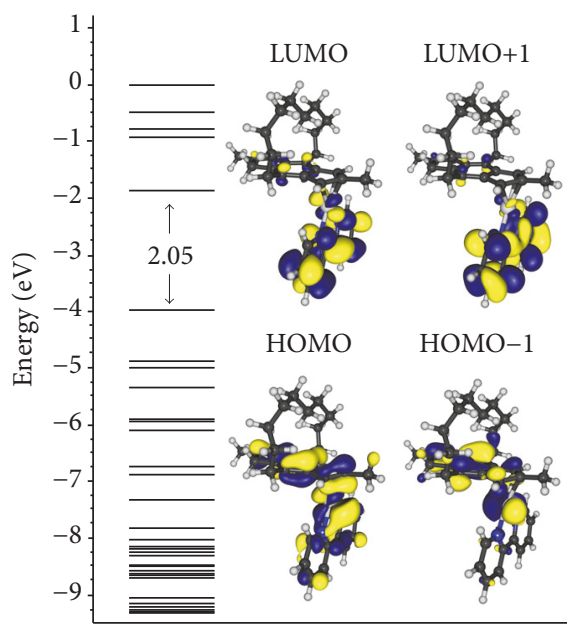

(c)
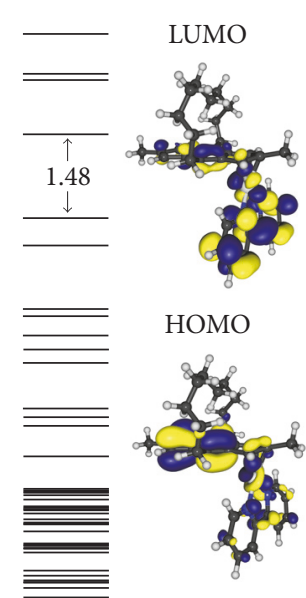

(d)
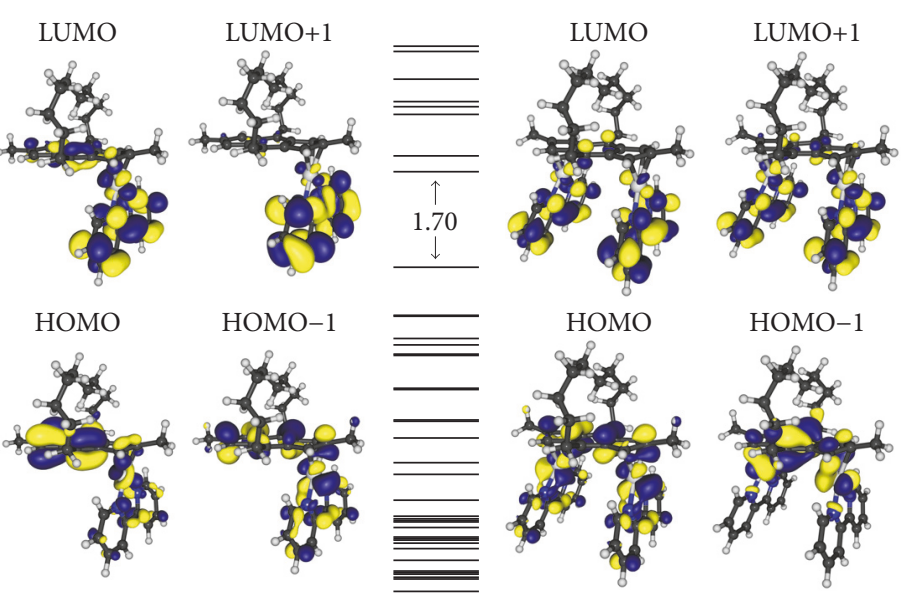

(e)

FIGURE 2: Compounds with Rh: (c) neutral monometallic, (d) monometallic monoanion, and (e) bimetallic systems with $\mathrm{L}=$ bipy and $\mathrm{R}=$ $\mathrm{CH}_{3}$.

Re holding ancillary ligands such as bipy and CO, containing $-\mathrm{CH}_{3}$ as $-\mathrm{R}$ substituent, present the most accurate $\mathrm{M}-\mathrm{M}$ distance around $5.43 \AA$ (Table 1). This distance corresponds to the $\mathrm{Cu}-\mathrm{Cu}$ distance of the complex reported by Bouwman et al. that catalyzed the transformation of $\mathrm{CO}_{2}$ to oxalate.

The ancillary ligands contribute steric effects towards the distances of the $\eta$ bonds between the metal and the $s$-Ic, while as bigger the ancillary ligand is, the shorter the distances among the metal and the carbon atoms are (Table 1). In this sense, it is also worth mentioning that while the $-\mathrm{R}$ substituents in the $s$-Ic are changed, some differences over the M-M distances were observed; however, no clear trend is found.

These facts lead us to conclude that the M-M distance can be tuned by adjusting different ancillary ligands and substituents over the $s$-Ic ligand.

In terms of the electronic structure, as consequence of the formation of the $s$-Ic dianion species with different $\mathrm{R}$ groups, the HOMO-LUMO gaps get smaller in comparison with the gap of the neutral species (Figures S1-S2 in Supplementary Material available online at https://doi.org/10.1155/ 2017/9101720). For the isolated ligand, it is also observed that the FMOs structures present contribution of the $s$-Ic ligand, except for the LUMO+1 of the dianionic compounds which is localized over the alkyl chain binding across the six-edge ring of $s$-Ic (Figures S1-S2). The change of the R groups does not show transcendental effect over the FMOs.

In cases of the metallic complexes, the localization of the FMOs does not change considerably when the comparison is made between the monometallic and the bimetallic species (see complexes with $\mathrm{Rh}$ as example in Figure 2), as they are formed by contribution of the orbitals extended over the $s$-Ic and over the transition metals.

The energy levels diagrams display that the FMOs of all the mononuclear and binuclear complexes are more stable than the free substituted $s$-Ic ligand. It is worth noticing that all studied systems with ligands $\mathrm{CO}$ show more stable occupied orbitals than the system with bipy.
It was also observed that the different studied peripheral $\mathrm{R}$ substituents of the $s$-Ic ring $\left(-\mathrm{H},-\mathrm{CH}_{3}\right.$, and $\left.-\mathrm{CH}_{2} \mathrm{CH}_{3}\right)$ show no contribution to the FMOs.

In general, all the complexes that have a bimetallic structure exhibit FMOs localized mainly over the ancillary ligands and the metal centers, although a slight variation of the FMO isosurfaces is observed specifically in the LUMO. This LUMO, in cases of voluminous ancillary ligands, is composed mainly for the ancillary ligands orbitals and the contribution of the metals decreases (Figures S3-S20 in the Supplementary Material).

In these systems, the mononuclear and the binuclear, the metals would have a dual role. The metal would be receiving electrons, therefore stabilizing the reduced fragments for the formation of the $\mathrm{C}-\mathrm{C}$ bond between two $\mathrm{CO}_{2}$ molecules. This is supported by the fact that the HOMO is localized over the fragment containing the metal and the ancillary ligands (Figure 2 and Figures S3-S20 in Supplementary Material). The localization of the FMOs over these regions of the molecules suggests their high reactivity towards any catalytic activity.

To assess the atomic charges in the metals of the studied family of compounds, a Mülliken analysis was carried out and the values are reported in Table 2. The formation of the complexes involves a charge transfer from the $s$-Ic and ancillary ligands to the metals as the atomic charges get less positive with respect to the oxidation state of the metals ( +1 for all metals in all cases). Significant charge transfer is observed for compounds containing $\mathrm{Rh}$ and $\mathrm{CO}$ as ancillary ligands, where it is known that the back-bonding effect of the CO ligand is present. In this sense, it is possible to state that in these systems the electron pair of each CO ligand donates more charge than it receives, which is evidenced in the slight negative charge over the metals. This behavior is followed by Re compounds containing $\mathrm{CO}$ which show atomic charges around 0.16 a.u. These values are significantly lower than the values obtained with Ir as metal center.

On the other hand, in cases of monometallic complexes, the charge transfer to the metals is bigger for the mononuclear 
TABLE 2: Atomic charges in a.u. for the metal centers of the monometallic (anion and neutral) and bimetallic systems.

(a)

\begin{tabular}{|c|c|c|c|c|c|c|c|c|c|c|c|c|}
\hline \multirow{3}{*}{$\mathrm{R}$} & \multicolumn{4}{|c|}{$\mathrm{M}=\mathrm{Ir}, \mathrm{L}_{n}=$ bipy } & \multicolumn{4}{|c|}{$\mathrm{M}=\mathrm{Rh}, \mathrm{L}_{n}=$ bipy } & \multicolumn{4}{|c|}{$\mathrm{M}=\mathrm{Re}, \mathrm{L}_{n, m}=$ bipy, $\mathrm{CO}$} \\
\hline & \multicolumn{2}{|c|}{ Mono } & \multicolumn{2}{|c|}{ Bim } & \multicolumn{2}{|c|}{ Mono } & \multicolumn{2}{|c|}{ Bim } & \multicolumn{2}{|c|}{ Mono } & \multicolumn{2}{|c|}{ Bim } \\
\hline & M1 ani & M1 neu & M1 & M2 & M1 ani & M1 neu & M1 & M2 & M1 ani & M1 neu & M1 & M2 \\
\hline $\mathrm{H}$ & 0.351 & 0.300 & 0.297 & 0.300 & 0.156 & 0.157 & 0.152 & 0.157 & 0.289 & 0.312 & 0.315 & 0.323 \\
\hline $\mathrm{CH}_{3}$ & 0.351 & 0.299 & 0.290 & 0.295 & 0.162 & 0.159 & 0.148 & 0.152 & 0.284 & 0.308 & 0.304 & 0.312 \\
\hline $\mathrm{CH}_{2} \mathrm{CH}_{3}$ & 0.349 & 0.298 & 0.287 & 0.295 & 0.151 & 0.048 & 0.142 & 0.147 & 0.278 & 0.301 & 0.300 & 0.309 \\
\hline
\end{tabular}

(b)

\begin{tabular}{|c|c|c|c|c|c|c|c|c|c|c|c|c|}
\hline \multirow{3}{*}{$\mathrm{R}$} & \multicolumn{4}{|c|}{$\mathrm{M}=\mathrm{Ir}, \mathrm{L}_{n, m}=\mathrm{CO}$} & \multicolumn{4}{|c|}{$\mathrm{M}=\mathrm{Rh}, \mathrm{L}_{n, m}=\mathrm{CO}$} & \multicolumn{4}{|c|}{$\mathrm{M}=\mathrm{Re}, \mathrm{L}_{n, m}=\mathrm{CO}$} \\
\hline & \multicolumn{2}{|c|}{ Mono } & \multicolumn{2}{|c|}{ Bim } & \multicolumn{2}{|c|}{ Mono } & \multicolumn{2}{|c|}{ Bim } & \multicolumn{2}{|c|}{ Mono } & \multicolumn{2}{|c|}{ Bim } \\
\hline & M1 ani & M1 neu & M1 & M2 & M1 ani & M1 neu & M1 & M2 & M1 ani & M1 neu & M1 & M2 \\
\hline $\mathrm{H}$ & 0.142 & 0.200 & 0.221 & 0.225 & -0.202 & -0.085 & -0.065 & -0.062 & 0.090 & 0.134 & 0.165 & 0.171 \\
\hline $\mathrm{CH}_{3}$ & 0.148 & 0.198 & 0.216 & 0.220 & -0.201 & -0.089 & -0.072 & -0.067 & 0.089 & 0.132 & 0.160 & 0.166 \\
\hline $\mathrm{CH}_{2} \mathrm{CH}_{3}$ & 0.149 & 0.197 & 0.214 & 0.219 & -0.203 & -0.093 & -0.077 & -0.071 & 0.086 & 0.130 & 0.158 & 0.164 \\
\hline
\end{tabular}

TABLE 3: Estimated energies for the HOMO and LUMO, chemical potential $(\mu)$, chemical hardness $(\eta)$, and electrophilicity $(\omega)$ calculated for the optimized ground state minima of the metallic complexes.

\begin{tabular}{|c|c|c|c|c|c|c|c|}
\hline Compound & & HOMO & LUMO & HL GAP & $\mu$ & $\eta$ & $\omega$ \\
\hline \multirow{3}{*}{$\mathrm{M}=\mathrm{Rh}, \mathrm{L}_{n}=$ bipy } & M1 ani & -2.68 & -1.20 & 1.48 & -1.94 & 0.74 & 2.55 \\
\hline & M1 neu & -3.97 & -1.82 & 2.16 & -2.90 & 1.08 & 3.89 \\
\hline & Bim & -3.61 & -1.90 & 1.71 & -2.76 & 0.85 & 4.46 \\
\hline \multirow{3}{*}{$\mathrm{M}=\mathrm{Rh}, \mathrm{L}_{n, m}=\mathrm{CO}$} & M1 ani & -3.15 & -0.64 & 2.52 & -1.89 & 1.26 & 1.42 \\
\hline & M1 neu & -5.13 & -1.44 & 3.69 & -3.28 & 1.84 & 2.92 \\
\hline & Bim & -5.18 & -1.77 & 3.41 & -3.47 & 1.70 & 3.54 \\
\hline \multirow{3}{*}{$\mathrm{M}=\mathrm{Re}, \mathrm{L}_{n, m}=$ bipy, $\mathrm{CO}$} & M1 ani & -2.76 & -1.43 & 1.33 & -2.10 & 0.66 & 3.31 \\
\hline & M1 neu & -4.27 & -1.95 & 2.32 & -3.11 & 1.16 & 4.17 \\
\hline & Bim & -4.11 & -1.87 & 2.24 & -2.99 & 1.12 & 3.99 \\
\hline \multirow{3}{*}{$\mathrm{M}=\mathrm{Re}, \mathrm{L}_{n, m}=\mathrm{CO}$} & M1 ani & -3.08 & -0.64 & 2.44 & -1.86 & 1.22 & 1.42 \\
\hline & M1 neu & -5.53 & -1.38 & 4.15 & -3.46 & 2.08 & 2.88 \\
\hline & Bim & -5.62 & -2.39 & 3.23 & -4.01 & 1.62 & 4.97 \\
\hline
\end{tabular}

anionic systems than for the neutral mononuclear ones, except the anionic mononuclear system containing Ir and bipy as ancillary ligands.

Taking into account these results, it is observed that $\mathrm{Rh}$ and Re bimetallic compounds might act as templates to carry out catalytic applications such as $\mathrm{CO}_{2}$ reduction reactions. These metals when forming part of these types of systems get rich in electron charge, which is in concordance with the fact that the occupied FMOs are localized over the metals. These facts lead us to consider these systems as better reducing agents than the compounds with Ir.

In order to rationalize the chemical reactivity, a set of global reactivity descriptors were computed in the framework of the conceptual density functional theory. The estimated chemical potential $(\mu)$, chemical hardness $(\eta)$, and electrophilicity $(\omega)$ have been analyzed [25-29]. This set of values is reported in Table 3. Moreover, the HOMO and LUMO energies and the HOMO-LUMO energy gaps are reported. For this analysis, we restricted the discussion to the complexes that are considered the best templates for catalytic reactions as stated above, that is, systems with $\mathrm{Rh}$ and $\mathrm{Re}$, $\mathrm{CO}$ and bipy as ancillary ligands, and $-\mathrm{CH}_{3}$ as peripheral substituent.

Parr defined $\mu$ in (1) as the infinitesimal change of energy of the system with respect to the electron number $N$ at a constant external potential of the nuclei $(v(\vec{r}))$, that is, the potential created by the nuclei. $\mu$ is related with its electronegativity as $-\chi$ and is associated with the feasibility of a system to exchange electron density with the environment at the ground state [25-29].

$\eta$ is calculated using the second-order derivative of the chemical potential (see (2)) and can be interpreted as the resistance of a molecule to change the electron density in presence of other species.

$$
\begin{aligned}
& \mu=\left(\frac{\partial E}{\partial N}\right)_{v(\vec{r})}=-\chi \\
& \eta=\frac{1}{2}\left(\frac{\partial^{2} E}{\partial N^{2}}\right)_{v(\vec{r})}=\frac{1}{2}\left(\frac{\partial \mu}{\partial N}\right)_{v(\vec{r})} .
\end{aligned}
$$



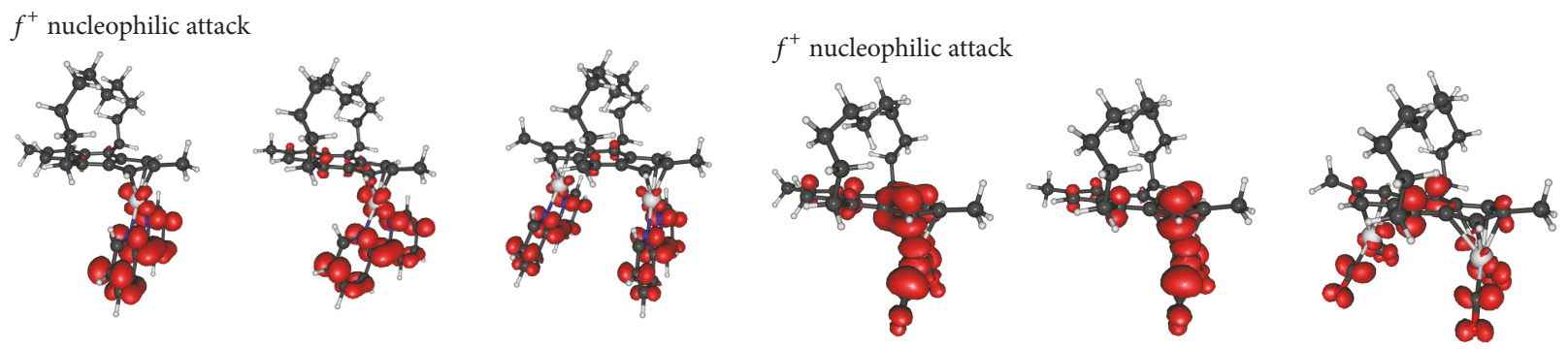

$f^{-}$electrophilic attack

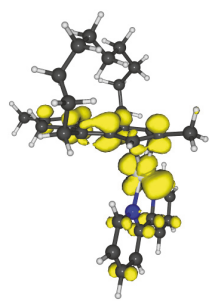

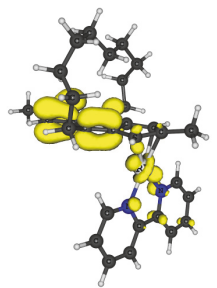

(a)

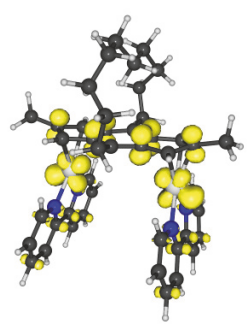

$f^{-}$electrophilic attack
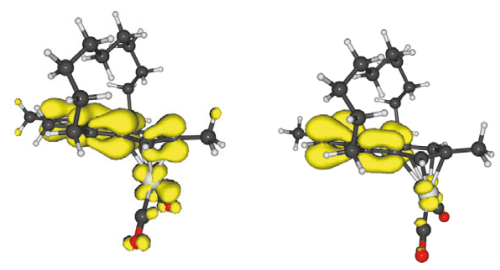

(b)

$f^{+}$nucleophilic attack
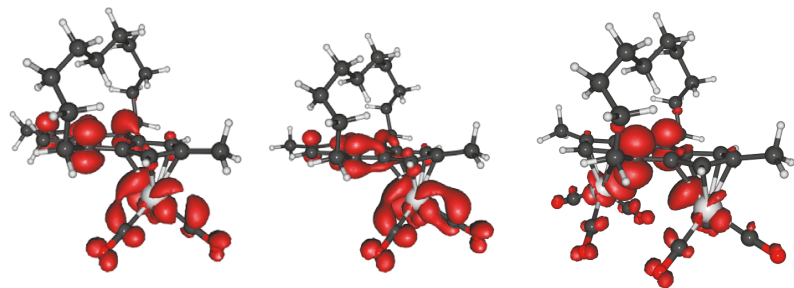

$f^{-}$electrophilic attack
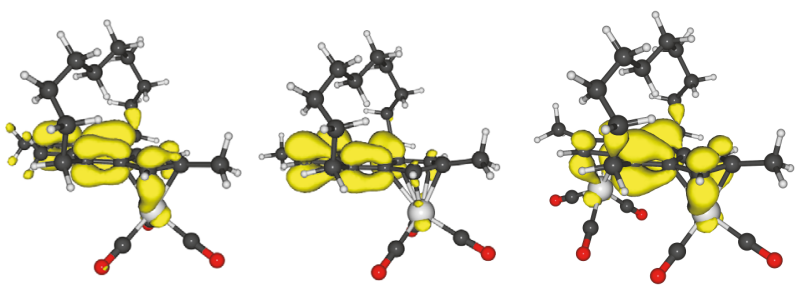

(c)

(d)

Figure 3: Condensed Fukui functions for nucleophilic $\left(f^{+}\right)$and electrophilic $\left(f^{-}\right)$attacks for compounds with metals (M) and ancillary ligands as follows: (a) Rh and bipy, (b) Rh and CO, (c) Re and bipy, CO, and (d) Re and CO. The neutral monometallic, anionic monometallic, and bimetallic complexes are shown.

In numerical applications, these reactivity indexes are calculated following approximations using Koopmans' theory and finite differences leading to (3). Here, $I$ and $A$ correspond to the ionization energy and electron affinity, while $E\left(\pi_{H}\right)$ and $E\left(\pi_{L}\right)$ correspond to the orbital energies of the HOMO and LUMO, respectively [25-28]:

$$
\begin{gathered}
\mu \approx-\frac{1}{2}(I+A) \approx \frac{1}{2}\left(E\left(\pi_{L}\right)+E\left(\pi_{H}\right)\right), \\
\eta \approx \frac{1}{2}(I-A) \approx \frac{1}{2}\left(E\left(\pi_{L}\right)-E\left(\pi_{H}\right)\right) .
\end{gathered}
$$

The $\omega$ index as defined in (4) measures the tendency of a molecule to receive electronic charge from a donor species.
Therefore, $\omega$ is considered as a sort of "electrophilicity power" [27-29]:

$$
\omega=\frac{\mu^{2}}{2 \eta}
$$

When bimetallic complexes are compared (see Table 3), the values of $\mu$ of systems with Rh and bipy $(-2.76 \mathrm{eV})$ and complex with Re and bipy and $\mathrm{CO}(-2.99 \mathrm{eV})$ are higher than values presented by systems with $\mathrm{Rh}, \mathrm{Re}$, and $\mathrm{CO}$ as ancillary ligands $(-3.47 \mathrm{eV}$ and $-4.01 \mathrm{eV}$, resp.). This suggests bigger reactivity of the first two named complexes towards electron donation. Hence, these complexes tend to react as source of electrons that enhance their possible behavior as catalytic templates for reduction reactions, such as the reduction of $2 \mathrm{CO}_{2}$ to $\mathrm{C}_{2} \mathrm{O}_{4}{ }^{2-}$. 
It is worth mentioning that $\mu$ of the monometallic neutral species adopts values similar to $\mu$ of the bimetallic complexes, which indicates that these systems can also act as strong electron donors. Finally, the anionic mononuclear species display the highest $\mu$ contemplated in the range of -1.86 to $-2.10 \mathrm{eV}$.

The $\eta$ decreases in the order mononuclear neutral > bimetallic > anionic mononuclear are reasonable with respect to the impact of the global reactivity/polarization indexes. The obtained trend indicates that the last two named systems are more reactive. In case of $\omega$, as expected, the anionic mononuclear systems show the lowest $\omega$ values and increase for the neutral and bimetallic compounds.

In order to clarify the dependency of the reactivity with the molecular structure, we also analyzed the condensed Fukui functions [25, 30, 31]. In Figure 3, we included the wavefunctions for nucleophilic $\left(f^{+}\right)$and electrophilic $\left(f^{-}\right)$ attacks. Considering that molecules may react with sites that show high or low electron density to carry out a reaction, the $f^{-}$plots depict that the metallic centers are able to follow a reaction pathway to carry out a reduction, as they have high density of electrons. These results are consistent with the known reactivity of ferrocene (and many other organometallic complexes) with any reducing species, where the reaction involves the formation of ferrocenium. Therefore, the reactivity of the herein studied molecules will depend on the interactions occurring in the metal of the complex with other species. Although these results are not a definitive evidence on how the mechanism of the chemical reactions might be, they are useful to understand the chemical behavior of the family of complexes.

\section{Conclusions}

A theoretical study of a new family of organometallic complexes was carried out. As it is observed, the results indicate that the bimetallic systems with Rh and Re holding ancillary ligands such as bipy and $\mathrm{CO}$ show the best properties to be active in a chemical reaction. This is supported by the fact that the most electron-rich portion of the molecule corresponds to the metallic centers and the s-Ic ligand. This is shown by the localization of the FMOs, the Mülliken charges, and the Fukui function plots. Furthermore, these complexes show the highest reactivity indexes. Specifically, the results display that the bimetallic complexes containing Rh and bipy and Re with bipy and $\mathrm{CO}$ would tend to be strong electron donors in a chemical reaction. This behavior is also observed for their monometallic neutral species.

Finally, in addition to all previously discussed results, it has been stated that an appropriate M-M distance around $5.43 \AA$ is an important parameter for a bimetallic compound to be able to perform the reductive coupling of two molecules of $\mathrm{CO}_{2}$ to oxalate. All the studied complexes show an M-M distance around this value, which would suggest that these complexes might show activity in this type of reactions.

This study will continue employing more ligands and metals, including the formation of oxalate, and then experiments will be carried out.

\section{Conflicts of Interest}

The authors declare that they have no conflicts of interest.

\section{Acknowledgments}

The authors acknowledge the financial support from the following projects: Fondecyt (Grants 1141138 and 1161416), CONICYT, Operating Expenses (Grant no. 21110092), and Milenio (RC120001 and REDES150042).

\section{References}

[1] K. Hafner, "Struktur und aromatischer charakter nichtbenzoider cyclisch konjugierter systeme," Angewandte Chemie, vol. 75, pp. 1041-1044, 1963.

[2] K. Hafner, "Masaichi saito; simetría," Pure and Applied Chemistry, vol. 2, pp. 950-969, 2010.

[3] E. E. Bunel, L. Valle, N. L. Jones et al., "Bis((pentamethylcyclopentadienyl)metal)pentalenes. A new class of highly delocalized, fused metallocenes," Journal of the American Chemical Society, vol. 110, no. 19, pp. 6596-6598, 1988.

[4] J. M. Manriquez, M. D. Ward, W. M. Reiff et al., "Structural and physical properties of delocalized mixed-valent $\left[\mathrm{Cp}^{\star} \mathrm{M}(\right.$ pentalene $\left.) \mathrm{M} / \mathrm{Cp}^{\star}\right] \mathrm{n}+$ and $\left[\mathrm{Cp}^{\star} \mathrm{M}(\right.$ indacene $\left.) \mathrm{M} / \mathrm{Cp}^{\star}\right] \mathrm{n}+$ $(\mathrm{M}, \mathrm{M} /=\mathrm{Fe}, \mathrm{Co}, \mathrm{Ni} ; \mathrm{n}=0,1,2)$ complexes," Journal of the American Chemical Society, vol. 117, no. 23, pp. 6182-6192, 1995.

[5] E. Esponda, C. Adams, F. Burgos et al., "New Rh derivatives of s-indacene active in dehydrogenative silylation of styrene," Journal of Organometallic Chemistry, vol. 691, no. 13, pp. 30113017, 2006.

[6] C. Morales-Verdejo, I. Martínez-Díaz, C. Adams et al., "New mono and bimetallic iron complexes derived from partially methylated s-indacene. Evidence of a trinuclear iron s-indacene complex," Polyhedron, vol. 69, pp. 15-24, 2014.

[7] C. Adams, C. Morales-Verdejo, V. Morales et al., "Heterobinuclear s-indacene rhodium complexes: synthesis and characterization," European Journal of Inorganic Chemistry, no. 6, pp. 784791, 2009.

[8] C. Morales-Verdejo, I. Martinez, D. Mac-Leod Carey et al., "Synthesis and structure of some heterobimetallic complexes having a polyalkyl-s-indacenyl spacer," Inorganica Chimica Acta, vol. 394, pp. 752-756, 2013.

[9] C. Song, "Global challenges and strategies for control, conversion and utilization of $\mathrm{CO} 2$ for sustainable development involving energy, catalysis, adsorption and chemical processing," Catalysis Today, vol. 115, no. 1-4, pp. 2-32, 2006.

[10] J. Notni, S. Schenk, H. Görls, H. Breitzke, and E. Anders, "Formation of a unique zinc carbamate by $\mathrm{CO} 2$ fixation: implications for the reactivity of tetra-azamacrocycle ligated Zn(II) complexes," Inorganic Chemistry, vol. 47, no. 4, pp. 13821390, 2008.

[11] B. Verdejo, J. Aguilar, E. García-España et al., "CO2 fixation by $\mathrm{Cu} 2+$ and $\mathrm{Zn} 2+$ complexes of a terpyridinophane aza receptor. Crystal structures of $\mathrm{Cu} 2+$ complexes, $\mathrm{pH}$-metric, spectroscopic, and electrochemical studies," Inorganic Chemistry, vol. 45, no. 9, pp. 3803-3815, 2006.

[12] A. Gennaro, A. A. Isse, J.-M. Savéant, M.-G. Severin, and E. Vianello, "Homogeneous electron transfer catalysis of the electrochemical reduction of carbon dioxide. Do aromatic 
anion radicals react in an outer-sphere manner?" Journal of the American Chemical Society, vol. 118, no. 30, pp. 7190-7196, 1996.

[13] T. Fujihara and Y. Tsuji, "Transition metal-catalyzed fixation of Carbon dioxide via carbon-carbon bond formation," Journal of the Japan Petroleum Institute, vol. 59, no. 3, pp. 84-92, 2016.

[14] E. García-España, P. Gaviña, J. Latorre, C. Soriano, and B. Verdejo, "CO2 fixation by copper(II) complexes of a terpyridinophane aza receptor," Journal of the American Chemical Society, vol. 126, no. 16, pp. 5082-5083, 2004.

[15] R. Angamuthu, P. Byers, M. Lutz, A. L. Spek, and E. Bouwman, "Electrocatalytic $\mathrm{CO}_{2}$ conversion to oxalate by a copper complex," Science, vol. 327, no. 5963, pp. 313-315, 2010.

[16] G. A. Van Albada, I. Mutikainen, O. Roubeau, U. Turpeinen, and J. Reedijk, "Ferromagnetic trinuclear carbonato-bridged and tetranuclear hydroxo-bridged $\mathrm{Cu}(\mathrm{II})$ compounds with 4,4'-dimethyl-2,2I-bipyridine as ligand. X-ray structure, spectroscopy and magnetism," Inorganica Chimica Acta, vol. 331, no. 1, pp. 208-215, 2002.

[17] M. J. Frisch, G. W. Trucks, H. B. Schlegel et al., Gaussian 09, Revision E.01, Gaussian Inc., Wallingford, Conn, USA, 2009.

[18] A. D. Becke, "Density-functional thermochemistry. III. The role of exact exchange," The Journal of Chemical Physics, vol. 98, no. 7, pp. 5648-5652, 1993.

[19] P. J. Stephens, F. J. Devlin, C. F. Chabalowski, and M. J. Frisch, "Ab Initio calculation of vibrational absorption and circular dichroism spectra using density functional force fields," Journal of Physical Chemistry, vol. 98, no. 45, pp. 11623-11627, 1994.

[20] W. R. Wadt and P. J. Hay, “Ab initio effective core potentials for molecular calculations. Potentials for main group elements $\mathrm{Na}$ to Bi," The Journal of Chemical Physics, vol. 82, no. 1, pp. 284298, 1985.

[21] P. J. Hay and W. R. Wadt, "Ab initio effective core potentials for molecular calculations. Potentials for $\mathrm{K}$ to Au including the outermost core orbitale," The Journal of Chemical Physics, vol. 82, no. 1, pp. 299-310, 1985.

[22] P. J. Hay and W. R. Wadt, "Ab initio effective core potentials for molecular calculations. Potentials for the transition metal atoms Sc to Hg," The Journal of Chemical Physics, vol. 82, no. 1, pp. 270283, 1985.

[23] M. J. Frisch, J. A. Pople, and J. S. Binkley, "Self-consistent molecular orbital methods 25. Supplementary functions for Gaussian basis sets," The Journal of Chemical Physics, vol. 80, no. 7, pp. 3265-3269, 1984.

[24] M. Cossi, N. Rega, G. Scalmani, and V. Barone, "Energies, structures, and electronic properties of molecules in solution with the C-PCM solvation model," Journal of Computational Chemistry, vol. 24, no. 6, pp. 669-681, 2003.

[25] L. R. Domingo, M. Ríos-Gutiérrez, and P. Pérez, "Applications of the conceptual density functional theory indices to organic chemistry reactivity," Molecules, vol. 21, no. 6, article 748, 2016.

[26] R. G. Pearson, "The electronic chemical potential and chemical hardness," Journal of Molecular Structure: THEOCHEM, vol. 255, pp. 261-270, 1992.

[27] R. G. Parr, L. V. Szentpály, and S. Liu, "Electrophilicity index," Journal of the American Chemical Society, vol. 121, no. 9, pp. 1922-1924, 1999.

[28] X. Zarate, E. Schott, T. Gomez, and R. Arratia-Pérez, "Theoretical study of sensitizer candidates for dye-sensitized solar cells: peripheral substituted dizinc pyrazinoporphyrazinephthalocyanine complexes," The Journal of Physical Chemistry A, vol. 117, pp. 430-438, 2013.
[29] P. K. Chattaraj and S. Giri, "Electrophilicity index within a conceptual DFT framework," Annual Reports on the Progress of Chemistry-Section C, vol. 105, pp. 13-39, 2009.

[30] C. E. Diaz-Uribe, W. Vallejo, W. Castellar et al., "Novel (E)-1(pyrrole-2-yl)-3-(aryl)-2-(propen-1-one) derivatives as efficient singlet oxygen quenchers: Kinetics and quantum chemical calculations," RSC Advances, vol. 5, no. 88, pp. 71565-71572, 2015.

[31] L. Arrue, T. Barra, M. B. Camarada, X. Zarate, and E. Schott, "Electrochemical and theoretical characterization of the electro-oxidation of dimethoxycurcumin," Chemical Physics Letters, vol. 677, pp. 35-40, 2017. 

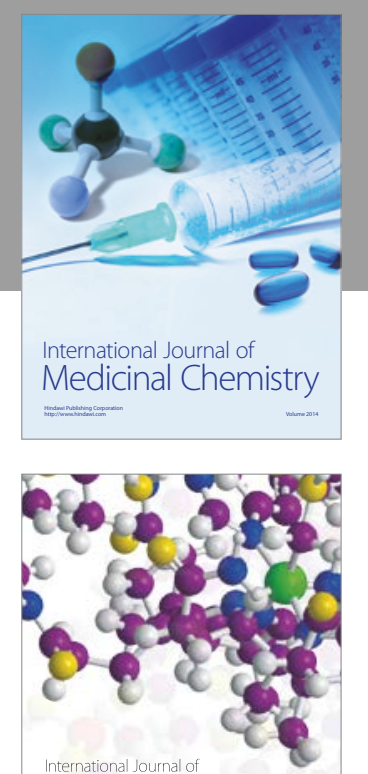

Carbohydrate Chemistry

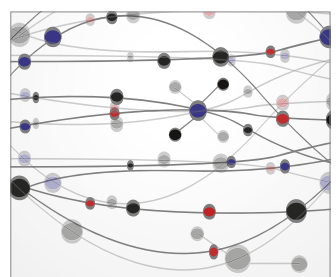

The Scientific World Journal
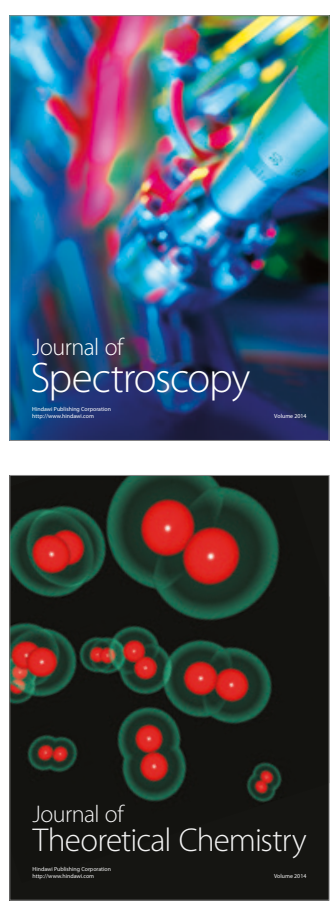
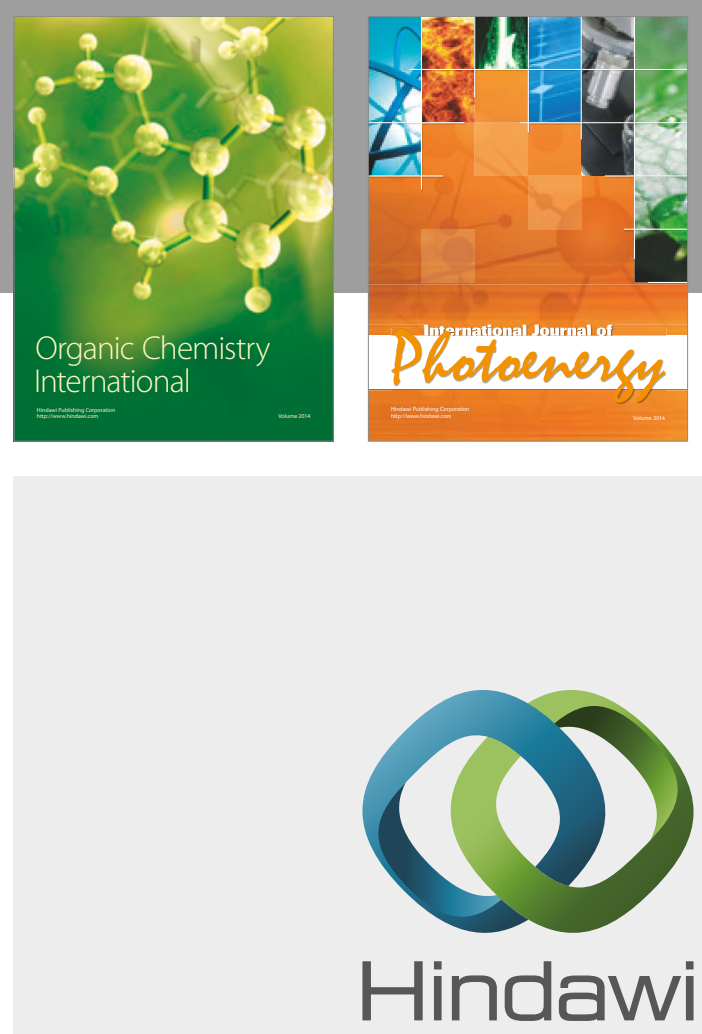

Submit your manuscripts at

https://www.hindawi.com

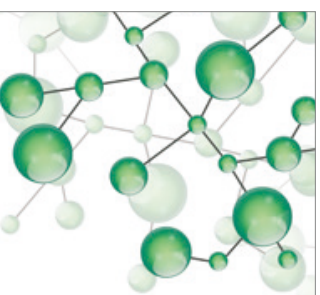

International Journal of

Inorganic Chemistry

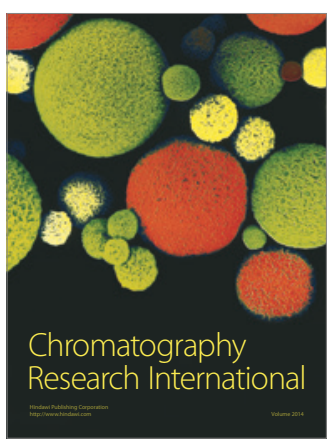

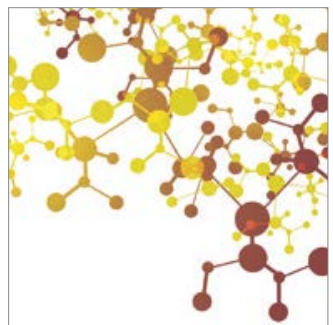

Applied Chemistry
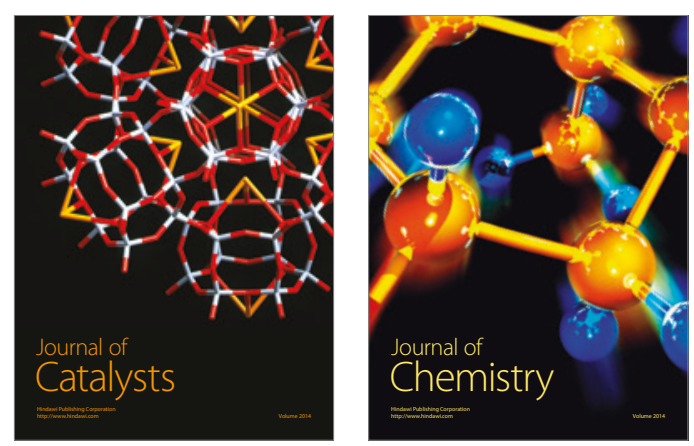
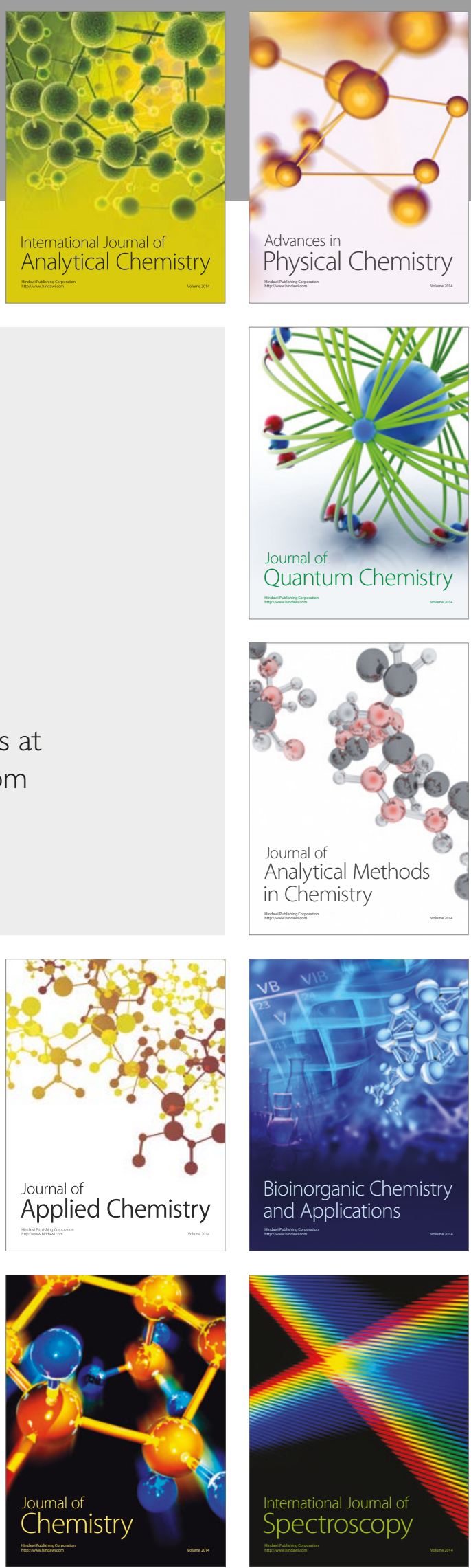